\title{
Local Buckling Behavior of Steel Sections Subjected to Fire
}

\author{
MARKUS KNOBLOCH \\ ETH Zurich \\ Institute of Structural Engineering - Steel, Timber and Composite Structures \\ 8093 Zurich \\ Switzerland
}

\begin{abstract}
The local buckling behavior of steel sections subjected to fire is strongly affected by the nonlinear stressstrain relationship of steel at elevated temperatures, non-uniform temperature distributions as well as thermal strains and stresses. This paper proposes a strain-based calculation model found to be particularly suitable for analyzing the load-carrying behavior of steel members subjected to local buckling and fire. This model uses strain-based capacity curves - based on a plastic mechanism and results of a comprehensive numerical parametric study - for calculating the load-shortening behavior of stiffened and unstiffened elements (internal compression parts and outstand flanges) under fire conditions. Additionally, the model takes into account thermal strains and stresses during heating in fire as well as uniform and nonuniform temperature distributions. Strain-based models avoid classification of cross-sections and consider local buckling even for compact cross-sections. The strain-based calculation model accords well with results obtained from a parametric study using the finite element approach.
\end{abstract}

KEYWORDS: steel, local buckling, strain-based calculation method, thermal stresses, structural design, finite element method, modeling.

\section{NOMENCLATURE LISTING}

\begin{tabular}{|c|c|c|c|}
\hline$b$ & width of a cross-sectional element & $N_{p l, \varepsilon, \theta}$ & $\begin{array}{l}\text { strain-based maximum axial } \\
\text { compression resistance }\end{array}$ \\
\hline$c_{t}$ & translational spring stiffness & $N_{p l, y, \theta}$ & resistance to axial force \\
\hline$e_{0, w}$ & equivalent geometric imperfection & & $\begin{array}{l}\text { thickness of a cross-sectional } \\
\text { element }\end{array}$ \\
\hline$f_{p, \theta}$ & $\begin{array}{l}\text { proportional limit at elevated } \\
\text { temperature }\end{array}$ & Greek & \\
\hline$f_{p 0.02, \theta}$ & $\begin{array}{l}0.2 \% \text {-proof stress at elevated } \\
\text { temperature }\end{array}$ & $\varepsilon_{C}$ & $\begin{array}{l}\text { strain corresponding to thermal } \\
\text { elongation }\end{array}$ \\
\hline$f_{y, \theta}$ & $\begin{array}{l}\text { effective yield strength at elevated } \\
\text { temperature }\end{array}$ & $\varepsilon_{\text {mec }}$ & mechanical strain \\
\hline$f_{\varepsilon, \theta}$ & $\begin{array}{l}\text { strain-dependent stress at elevated } \\
\text { temperature }\end{array}$ & $\varepsilon_{\text {th }}$ & thermal strain \\
\hline$k$ & spring stiffness ratio & $\varepsilon_{\mathrm{th}, \sigma}$ & thermal strain producing stress \\
\hline$k_{p 0.2, \theta}$ & $\begin{array}{l}\text { reduction factor for the } 0.2 \% \text {-proof } \\
\text { stress at elevated temperature }\end{array}$ & $\varepsilon_{\text {tot }}$ & total strain \\
\hline$k_{y, \theta}$ & $\begin{array}{l}\text { reduction factor for the effective } \\
\text { yield strength at elevated } \\
\text { temperature }\end{array}$ & $\theta_{a}$ & steel temperature \\
\hline$M / M_{p l, \alpha, \varepsilon, \theta}$ & $\begin{array}{l}\text { strain-based non-dimensional } \\
\text { resistance to bending moment }\end{array}$ & $\psi_{\varepsilon}$ & $\begin{array}{l}\text { strain ratio of the element (ratio } \\
\text { between the translational }\end{array}$ \\
\hline$M_{p l, \alpha, \varepsilon, \theta}$ & $\begin{array}{l}\text { strain-based maximum bending } \\
\text { moment resistance }\end{array}$ & & $\begin{array}{l}\text { displacements at the longitudinal } \\
\text { edges of cross-section elements) }\end{array}$ \\
\hline$N / N_{p l, \varepsilon, \theta}$ & $\begin{array}{l}\text { strain-based non-dimensional } \\
\text { resistance to axial force }\end{array}$ & & \\
\hline
\end{tabular}




\section{INTRODUCTION}

Fire design has become an important factor in the safe and economical design of steel structures and has attracted worldwide attention during recent years. In addition to sound construction practice for steel structures in fire, it is necessary to have safe, economical, and easy applicable calculation models for the fire design of steel members, especially in case of stability failure. Local buckling and the material behavior of steel at elevated temperatures have a strong influence on the cross-sectional resistance of steel sections in fire. In fire, steel members heat up at a rate depending on the fire conditions. The temperature distribution of the steel cross-sections can be either uniform or non-uniform. The distribution depends on the cross-section, the fire protection, and the heating conditions. At elevated temperatures in fire, the strength and stiffness of steel decreases rapidly, and the stress-strain relationship becomes distinctly nonlinear (cp. Fig. 1a). As a result, very large strains are required to reach yield strength and to take benefit of increasing the cross-sectional capacity due to plastification. Therefore, local buckling in fire conditions needs to be considered for more cross-sections than is usual in ambient temperature design.

The common European fire design models [1] for thin-walled cross-sections are based on research results of Ala-Outinen and Myllymäki [2] and Ranby [3]. They adopt the ambient temperature approach including the effective width method - for fire conditions. Further recent studies using the effective width approach and the cross-section classification in fire design are presented by Feng and Wang [4] and Heidarpour and Bradford [5]. The common calculation methods and the classification of cross-sections, however, do not consider the large strains required to reach yield strength at elevated temperatures. Additionally, the common methods are not appropriate for considering local buckling of compact sections as well as the influence of non-uniform temperature distributions, the nonlinear material behavior of steel at elevated temperatures, and thermal strains and stresses on the load-carrying behavior of steel sections. It was thus the aim of the study to review the current fire design procedure and to develop a novel calculation model for steel members subjected to fire, taking into account local buckling effects.

This paper first reviews common calculation models for local buckling in fire. A novel calculation method using strain-based capacity curves for unstiffened and stiffened elements at elevated temperatures is then developed. Finally, the strain-based calculation model for stiffened elements in fire is extended for considering uniform and non-uniform temperature distributions as well as thermal strains and stresses.

\section{CALCULATION MODELS FOR LOCAL BUCKLING IN FIRE}

Open steel sections, such as C, U, Z, and I sections, consist of stiffened and unstiffened elements (internal compression parts and flange outstands). A stiffened element is defined as a flat element where both edges parallel to the direction of loading are supported, and an unstiffened element is a flat element where only one longitudinal edge is supported. For design, steel sections are usually considered to be made up of elements which are simply supported on three and four sides (Fig. 1b). If these elements are sufficiently slender, the section will develop local buckling at a load less than the yield resistance calculated with yield strength and gross cross-sectional area. The section will continue to carry additional loads by means of the redistribution of stress after local buckling occurs (post-buckling behavior).

Common stress-based design leads to classification and associated geometric maximum width-to-thickness ratios. For the design of steel structures, static analysis may be performed using elastic and plastic moment distribution for the system and elastic or plastic stress distribution for the cross-section (Fig. 2b), resulting in the plastic-plastic, elastic-plastic, and elastic-elastic design methods. The demand for rotational capacity in the cross-section increases from elastic-elastic to plastic-plastic design. For thin-walled cross-section, the available rotational capacity may even be insufficient for an elastic-elastic design because of local buckling. In this case, the decrease in load-carrying capacity due to local buckling can be taken into account using different methods remaining in elastic-elastic-reduced design. Often four cross-section classes are connected to these methods (Fig. 2a). Classification is an easy and simplified way to satisfy the various ductility requirements. Every cross-section has ductility, but even compact sections may develop local buckling under large strains. After local buckling occurs, the moment-curvature graph of each crosssection has a decreasing branch (Fig. 2a). However, the strain at which local buckling occurs is different: thin-walled cross-sections buckle under small strains below proportional strain, while compact sections may buckle only under strains much higher than yield strain at ambient temperature. 
(a)

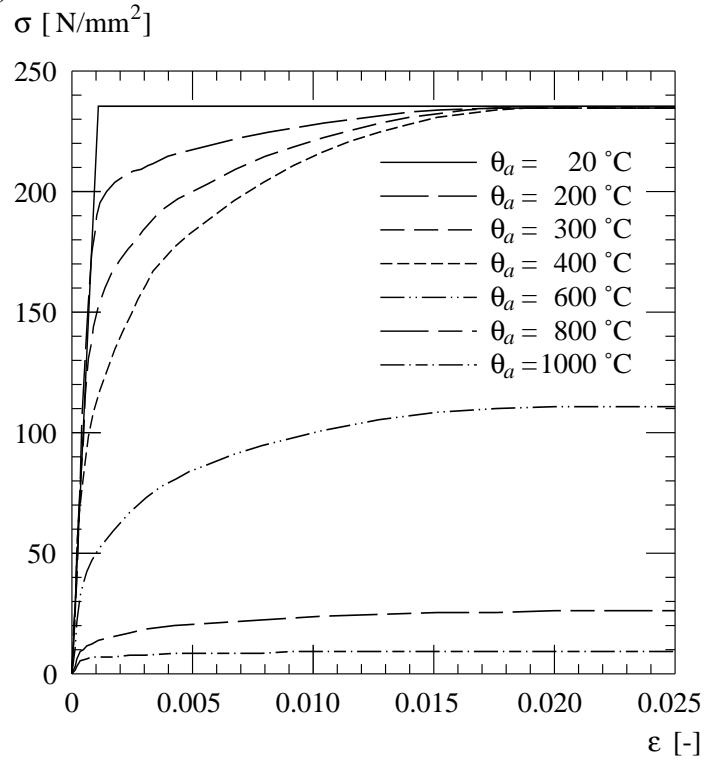

(b)
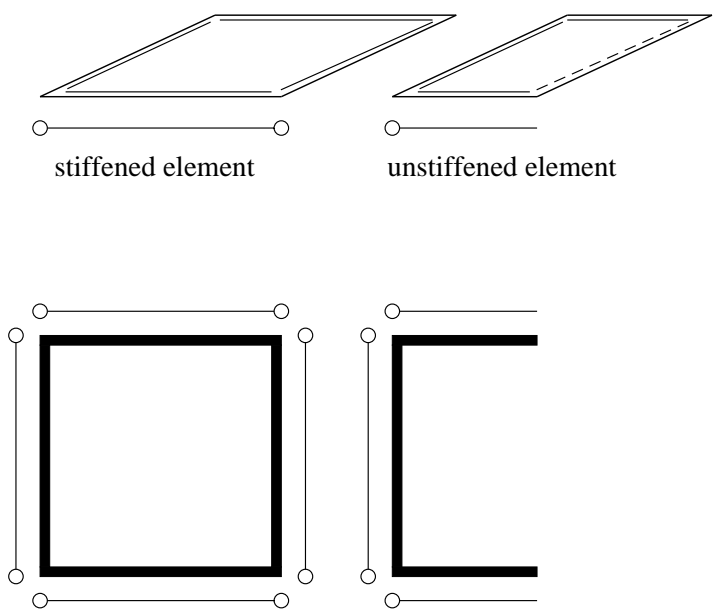

Fig. 1. (a) Stress-strain relationship at elevated temperatures for steel grade S235 according to EN 1993-1-2 [1]; (b) cross-section with stiffened and unstiffened elements.

In fire design, cross-sections are often for simplicity classified in the same way as in ambient temperature design (sometimes considering the temperature-dependent ratio of the yield strength and elastic modulus), although the rounded stress-strain relationship and the larger strains required to reach yield strength due to the nonlinear material behavior should be considered. The yield strain at elevated temperatures is multiple times higher than the maximum strains used for developing effective widths and maximum width-tothickness ratios in the plastic state at ambient temperature [6]. Even compact sections suitable for plastic design at ambient temperature develop local buckling at large strains necessary for reaching the effective yield strength in fire [7]. A simplified model based on elastic strains, presented in [7], shows the significant influence of strains on the cross-section classification, especially for sections predominantly subjected to axial compression.

(a)

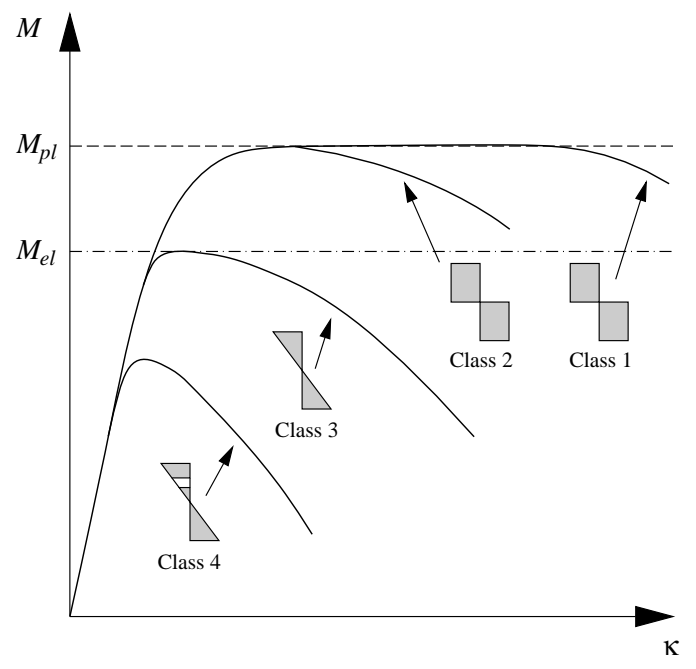

(b)

\section{Static analysis}
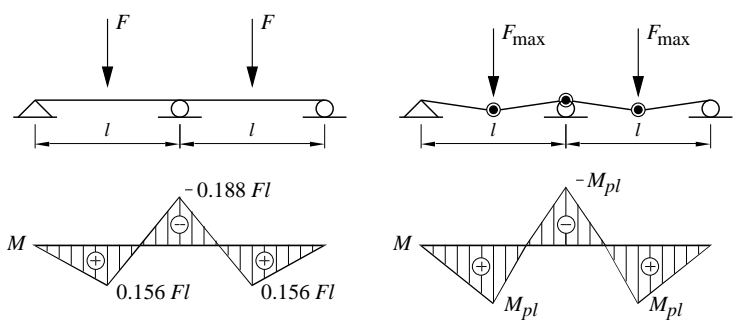

elastic

plastic hinge design

Cross-sectional resistance

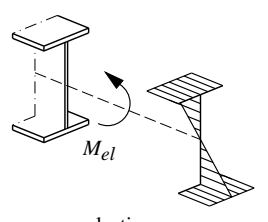

elastic

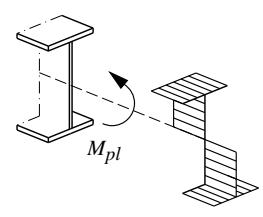

plastic

Fig. 2. (a) Moment-curvature graph for class 1 to 4 members with linear-elastic perfectly-plastic stressstrain relationship; (b) elastic and plastic design. 
The common calculation models for fire design, e.g. [1], adopt the ambient temperature stress-based approach and consider local buckling effects only for thin-walled cross-sections - which develop local buckling even/almost at ambient temperature - by using the critical temperature approach or the effective width method in conjunction with the temperature-dependent $0.2 \%$-proof stress. The effective width method, originally developed by von Kármán, Sechler and Donnell [8], simplifies the redistribution of stress by assuming that certain areas of the cross-section remain effective, the remainder being totally ineffective and to be regarded as a "hole" in the cross-section. For the fire design of cross-sections appropriate for plastic or elastic design (class 1-3 sections), EN 1993-1-2 [1], for example, uses the temperature-dependent strength reached at $2 \%$ strain as an effective yield strength. The common stressbased calculation methods are not appropriate for considering local buckling of compact sections as well as the influence of non-uniform temperature distributions, the nonlinear material behavior of steel at elevated temperatures, and thermal strains and stresses on the load-carrying behavior of steel sections. Strain-based calculation methods, however, are found to be suitable in fire design. Strain-based methods separate the different influences on the load-carrying capacity, in particular the local buckling effect and the effect of the nonlinear stress-strain relationship. These approaches avoid classification, consider local buckling even for compact sections at large strains, and can be used for the design of all cross-sections. Additionally, the methods can consider the influence of the nonlinear stress-strain relationship of steel at elevated temperatures by using the actual strain-dependent stress obtained from either material tensile coupon tests or constitutive laws given in standards as well as uniform and non-uniform heating effects on the local buckling and the load-carrying behavior. Strain-based calculation methods for fire design use either strainbased formulae for effective widths [9], the yield line approach [10], or strain-based capacity curves based on the plastic mechanism analysis or numerical studies using the finite element approach applied in this study. Table 1 summarizes the characteristic features of strain-based calculation methods and compares these methods to common stress-based methods.

Table 1. Comparison of stress-based and strain-based calculation methods.

\begin{tabular}{|l|c|c|}
\hline & Stress-based calculation & Strain-based calculation \\
\hline Calculation methods & $\begin{array}{l}\text { - Effective width method } \\
\text { - Reduced stress method } \\
\text { - Reduced thickness method }\end{array}$ & $\begin{array}{l}\text { - Strain-based effective width } \\
\text { method } \\
\text { - Plastic mechanism analysis } \\
\text { - Strain-based capacity curves }\end{array}$ \\
\hline Separation of the influences & no & yes \\
\hline Classification of the cross-sections & required & not required \\
\hline $\begin{array}{l}\text { Consideration of local buckling for } \\
\text { compact sections }\end{array}$ & no & yes \\
\hline $\begin{array}{l}\text { Consideration of the nonlinear } \\
\text { stress-strain relationship }\end{array}$ & no & yes \\
\hline $\begin{array}{l}\text { Design stress } \\
\text { Calculation of the ultimate load }\end{array}$ & $\begin{array}{l}\text { - Effective yield strength } f_{y, \theta} \\
0.2 \% \text {-proof stress } f_{p 0.2, \theta}\end{array}$ & - Strain-dependent stress $f_{\varepsilon, \theta}$ \\
\hline $\begin{array}{l}\text { Calculation of the load-shortening } \\
\text { behavior }\end{array}$ & yes & no \\
\hline
\end{tabular}

\section{STRAIN-BASED CAPACITY CURVES}

The strain-based capacity curves consider the local buckling effects on the load-carrying behavior of steel sections at uniform elevated temperatures in fire. The capacity curves are used for calculating the entire load-shortening behavior including the ultimate capacity of unstiffened and stiffened elements. Therefore, the capacity curves separate the local buckling effects from the influence of the nonlinear stress-strain relationship of steel at elevated temperatures on the load-shortening behavior. The capacity curves are independent of the temperature and can be used for all temperatures. These curves depend on the shortening $\varepsilon_{\mathrm{tot}}$, the width-to-thickness ratio $b / t$, the equivalent geometric imperfection $e_{0, w}$ for small strains, the strain ratio $\psi_{\varepsilon}$ of the mechanical loading (ratio between the translational displacements at the longitudinal edges of the element) and the boundary conditions. The strain-based capacity curves for unstiffened elements (outstand flanges) in pure compression are based on a plastic mechanism analysis; the 
curves for stiffened elements (internal compression elements) are based on a comprehensive numerical study using the finite element approach.

\section{Unstiffened elements}

Unstiffened elements in pure compression $\left(\psi_{\varepsilon}=1.0\right)$ have a major effect on the load-carrying capacity of steel sections, typically used for steel structures. Flanges, for example, decisively influence the resistance of I sections subjected to bending moments. The local plastic mechanism used to describe the loaddeflection behavior of unstiffened elements at elevated temperatures in fire consisted of two inclined yield lines and one yield line perpendicular to the direction of thrust (Fig. 3), cp. [11]. The relationship between the local buckling deflection $w_{y}$ including equivalent geometric imperfections and the longitudinal displacement (shortening) $\varepsilon_{\text {tot }}$ was used for the analytical description of the non-dimensional axial load-end shortening behavior and the strain-based capacity curves (Fig. 4), cp. [12]. The strain-based capacity curves (Fig. 4) give the axial force $N$ of unstiffened elements relative to the strain- and temperature-dependent maximum axial resistance $N_{p l, \varepsilon, \theta}$ as a function of the end shortening $\varepsilon_{\text {tot }}$, the width-to-thickness ratio $b / t$, and the equivalent geometric imperfection $e_{0, w}$. The maximum axial resistance $N_{p l, \varepsilon, \theta}$ give the temperaturedependent actual maximum resistance (without local buckling) as a function of the shortening $\varepsilon_{\text {tot }}$. This resistance is calculated as the product of the gross cross-sectional area and the temperature- and straindependent stress $f_{\varepsilon, \theta}$ determined from either material tensile coupon tests or constitutive laws given in standards, e.g. EN 1993-1-2. Details of the plastic mechanism, the development of the strain-based capacity curves, and a comparison of the results according to the strain-based method to numerical results are given in $[7,10]$.

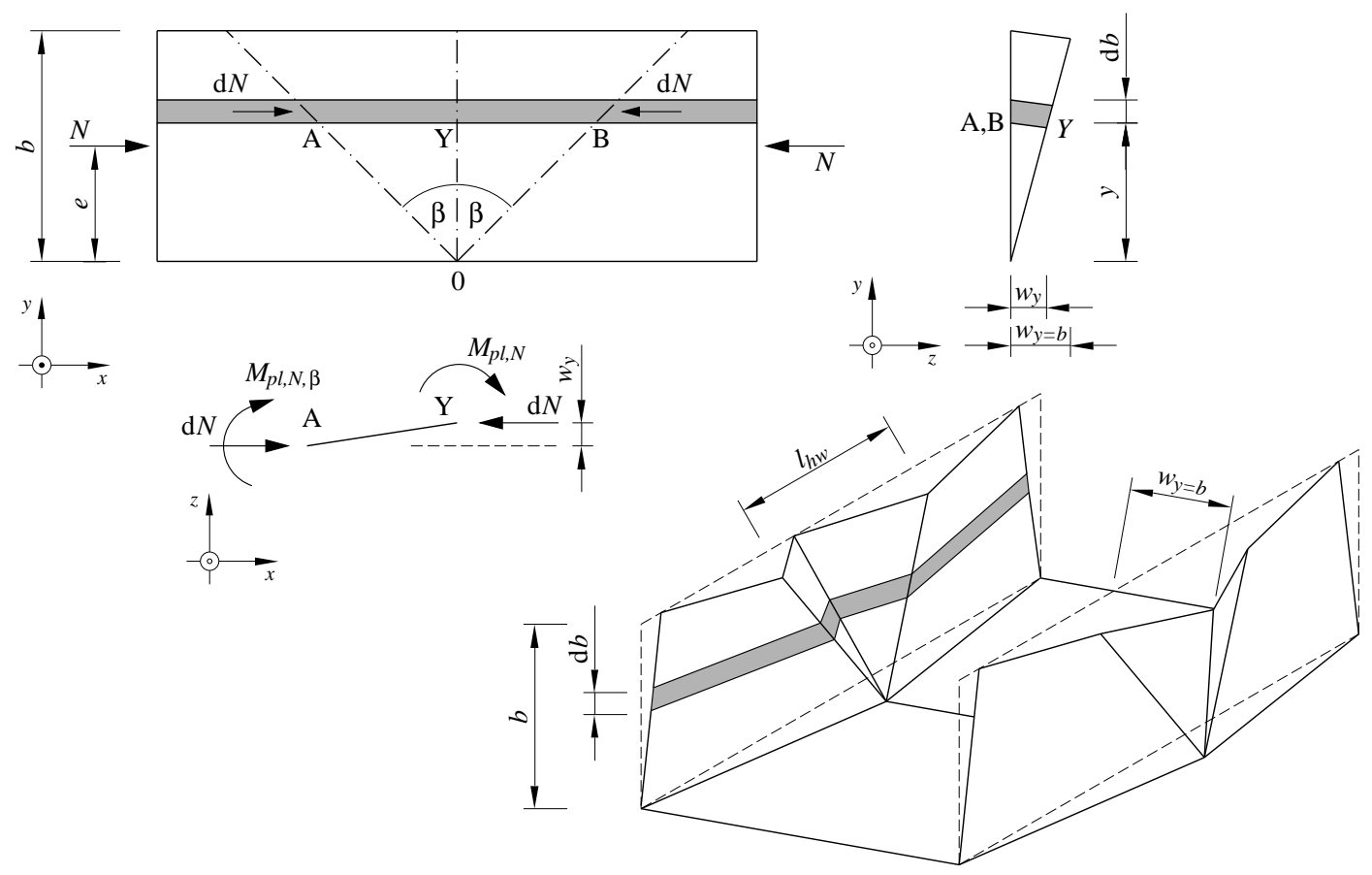

Fig. 3. Plastic mechanism used for the strain-based capacity curves of unstiffened elements. 

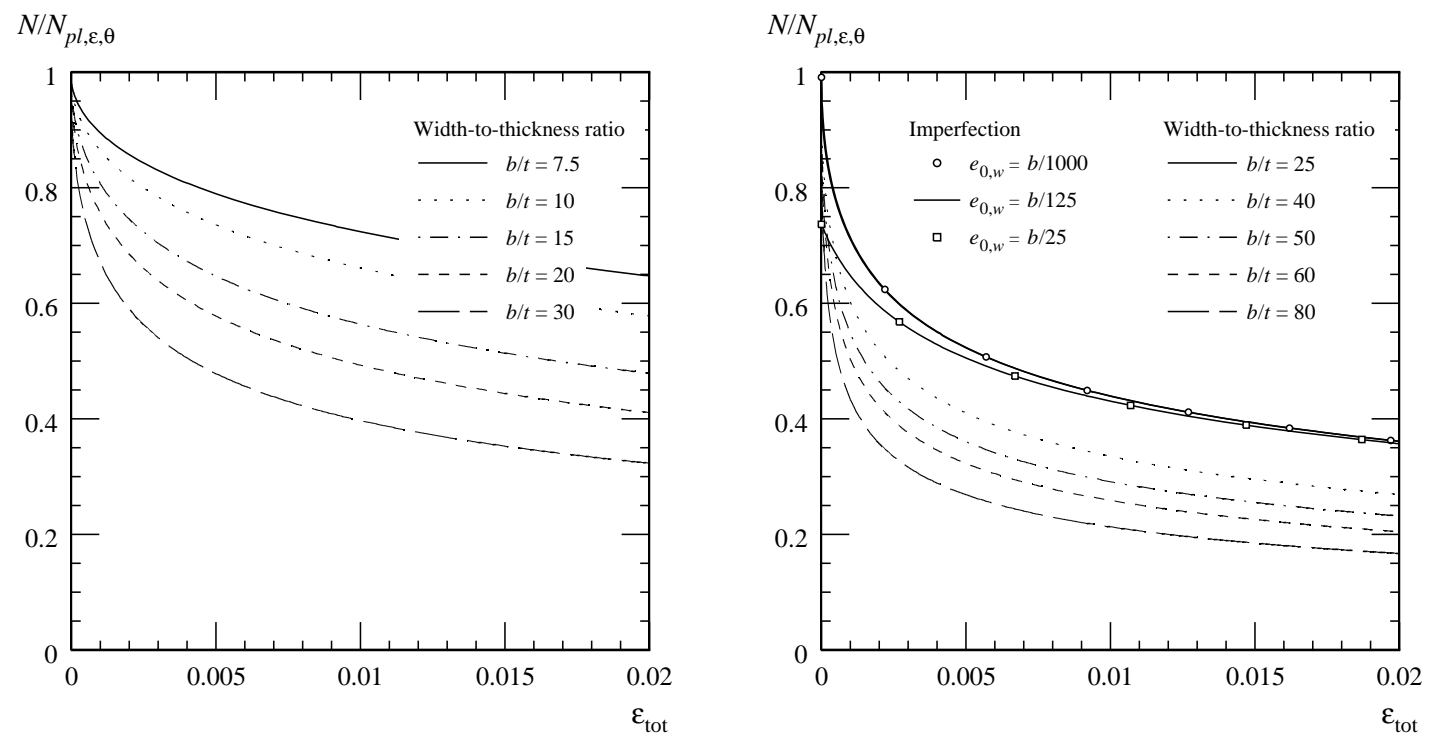

Fig. 4. Strain-based capacity curves for unstiffened elements at elevated temperature in fire $\left(\psi_{\varepsilon}=1.0\right)$.

\section{Stiffened elements}

Stiffened elements, like webs of I sections, are subjected to pure compression $\left(\psi_{\varepsilon}=1.0\right)$, pure bending $\left(\psi_{\varepsilon}\right.$ $=-1.0)$ or combined compression and bending $\left(-1.0<\psi_{\varepsilon}<1.0\right)$. The strain-based capacity curves for stiffened elements are developed from the results of a comprehensive numerical parametric study using the finite element approach. By using the finite element program Abaqus [13] geometrical and physical nonlinear calculations were performed. In the parametric study the internal axial forces and bending moments were calculated as a function of the maximum end shortening $\varepsilon_{\text {tot }}$, the width-to-thickness ratio $b / t$, the steel temperature $\theta_{a}$, the boundary conditions (simply supported or fixed), and the strain ratio $\psi_{\varepsilon}$. The stress-strain relationships used in the numerical calculations were based on the models on EN 1993-1-2 for steel grade S235 at elevated temperatures. The numerical calculations were performed displacement controlled with different strain ratios $\psi_{\varepsilon}$ using 4-node and 9-node shell elements respectively (designated as S4 and S9R5 of the Abaqus element library). The maximum total strain, calculated as the quotient of the maximum displacement $u$ of the lateral edge and the lengths of the elements $a$, was $\varepsilon_{\text {tot }}=u / a=2 \%$ for elements in pure compression and $4 \%$ for elements in bending. The initial imperfections were scaled from eigenvectors according to the lowest eigenvalue. The values for the equivalent geometrical imperfections were chosen as $e_{0, w}=b / 250$. The critical length-to-width ratio $\alpha$ depends on the boundary conditions and the strain ratio $\psi_{\varepsilon}$, and was taken as $\alpha=1$ for stiffened elements which are simply supported in uniform compression for example. Further details of the parametric study and the finite element model are given in [7].

Figure 5 exemplarily shows the non-dimensional axial load-end shortening behavior of stiffened elements simply supported on all sides at different temperatures possessing width-to-thickness ratios of 30 (left) and 120 (right). The compact elements $(b / t=30)$ are suitable for plastic design (class 1$)$ at ambient temperature and elastic-plastic design (class 2) in fire according to EN 1993-1-2. Unlike ambient temperature, the temperature-dependent plastic resistance $N_{p l, y, \theta}$ - calculated as the product of the gross cross-sectional area and the temperature-dependent yield strength $f_{y, \theta}$ at $2 \%$ strain - was not reached at elevated temperatures. The slender elements $(b / t=120)$ developed local buckling even at small strains less than yield strain at ambient temperature and have to be designed using e.g. the effective width method at both ambient and elevated temperatures for considering local buckling effects. Figure 5 (right) additionally compares the resistance for slender elements $(b / t=120)$ according to EN 1993-1-2 with numerical results. The analytical calculation method (EN 1993-1-2) for slender elements (class 4) in pure compression led to adequate design results in comparison to the numerical results. The temperature-dependent shape of the nonlinear stress-strain relationship, and in particular the ratio of the proportional limit $f_{p, \theta}$ to the yield strength $f_{y, \theta}$, 
illustrated in Table 2, markedly affected the non-dimensional axial resistance $N / N_{p l, y, \theta}$ and the axial loadshortening behavior. A large ratio $f_{p, \theta} / f_{y, \theta}$, for example at $200^{\circ} \mathrm{C}$, led to a large non-dimensional resistance reached at a small end shortening, whilst a small ratio $f_{p, \theta} / f_{y, \theta}$, for example at $700^{\circ} \mathrm{C}$, resulted in more ductile behavior and a smaller non-dimensional resistance reached at a larger end shortening (Fig. 5).

Table 2. Ratio between the proportional limit $f_{p, \theta}$ and the effective yield strength $f_{y, \theta}$ according to [1].

\begin{tabular}{cccccccccc}
\hline Temperature $\theta_{a}\left[{ }^{\circ} \mathrm{C}\right]$ & 20 & 200 & 300 & 400 & 500 & 600 & 700 & 800 & 900 \\
\hline$f_{p, \theta} / f_{y, \theta}$ & 1.0 & 0.807 & 0.613 & 0.42 & 0.462 & 0.383 & 0.326 & 0.455 & 0.625 \\
\hline
\end{tabular}
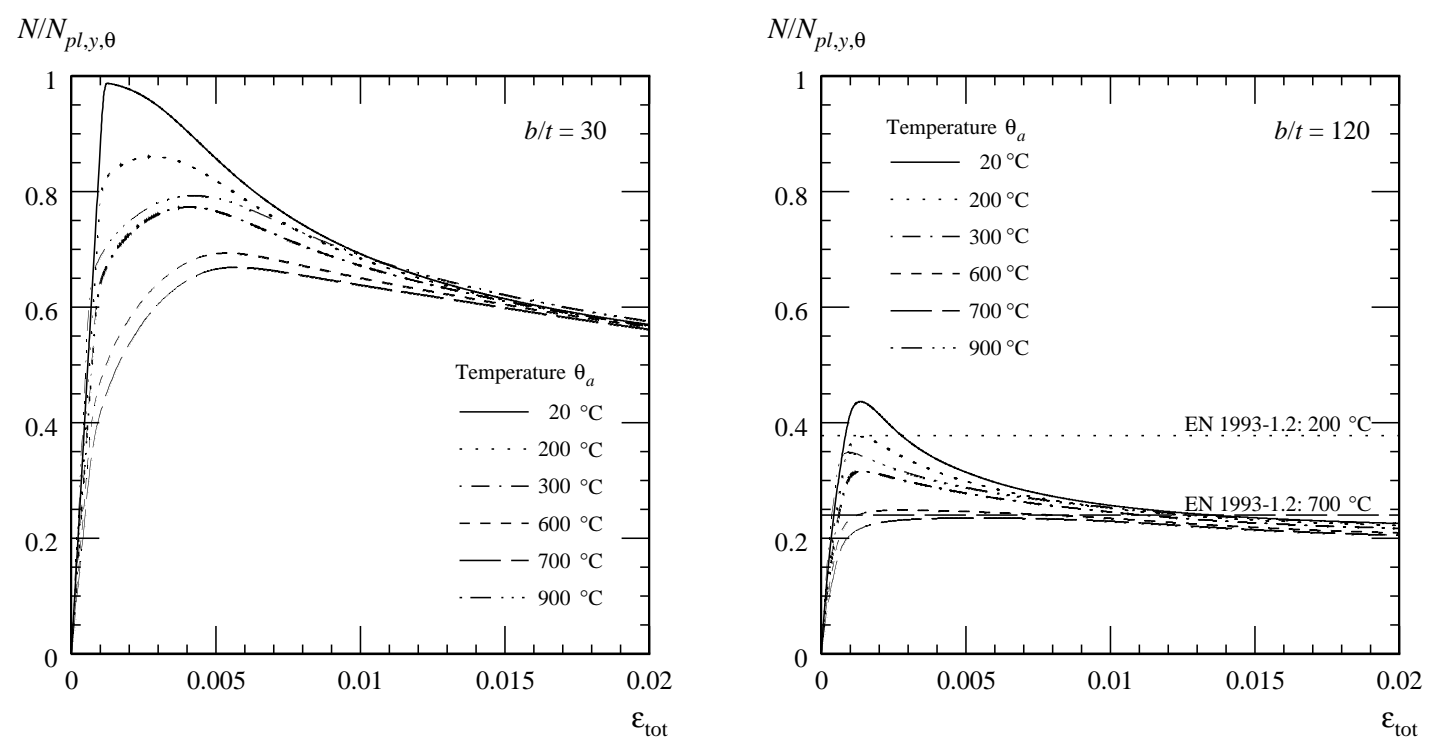

Fig. 5. Non-dimensional axial load-shortening behavior of compact (left) and slender (right) stiffened elements at elevated temperatures in fire $\left(\psi_{\varepsilon}=1.0\right)$

The axial load-shortening curves of Fig. 5 consider both the decrease of the load-carrying capacity due to local buckling effects and the increase of the load-carrying capacity due to the strain hardening as a result of the nonlinear material behavior. A separation and quantification of both influences were not possible using the non-dimensional value $N / N_{p l, y, \theta}$. However, it was also possible to give the axial force $N$ relative to the strain-dependent maximum axial resistance $N_{p l, \varepsilon, \theta}$ calculated as the product of the gross cross-sectional area and the temperature- and strain-dependent stress $f_{\varepsilon, \theta}$. The difference between the axial force and the strain-dependent maximum resistance showed the influence of local buckling. Figure 6 shows the nondimensional strain-dependent axial load-shortening behavior of stiffened elements possessing width-tothickness ratios of 30 (Fig. 6 left) and 120 (Fig. 6 right) at different elevated temperatures. These different strain-dependent axial load-shortening curves were almost congruent, although the constitutive laws for steel are not similar at different temperatures. Minor variations of the non-dimensional strain-dependent axial load-shortening curves were primarily a result of the polygonal approximation of the stress-strain relationships. The influence of the Tangent modulus in the plastic range at elevated temperature could be neglected. The non-dimensional strain-dependent axial load-shortening curves were therefore, for simplification, independent of the temperature and their stress-strain relationship. Unified axial loadshortening curves could be used as strain-based capacity curves for stiffened elements under fire conditions (Fig. 7). 

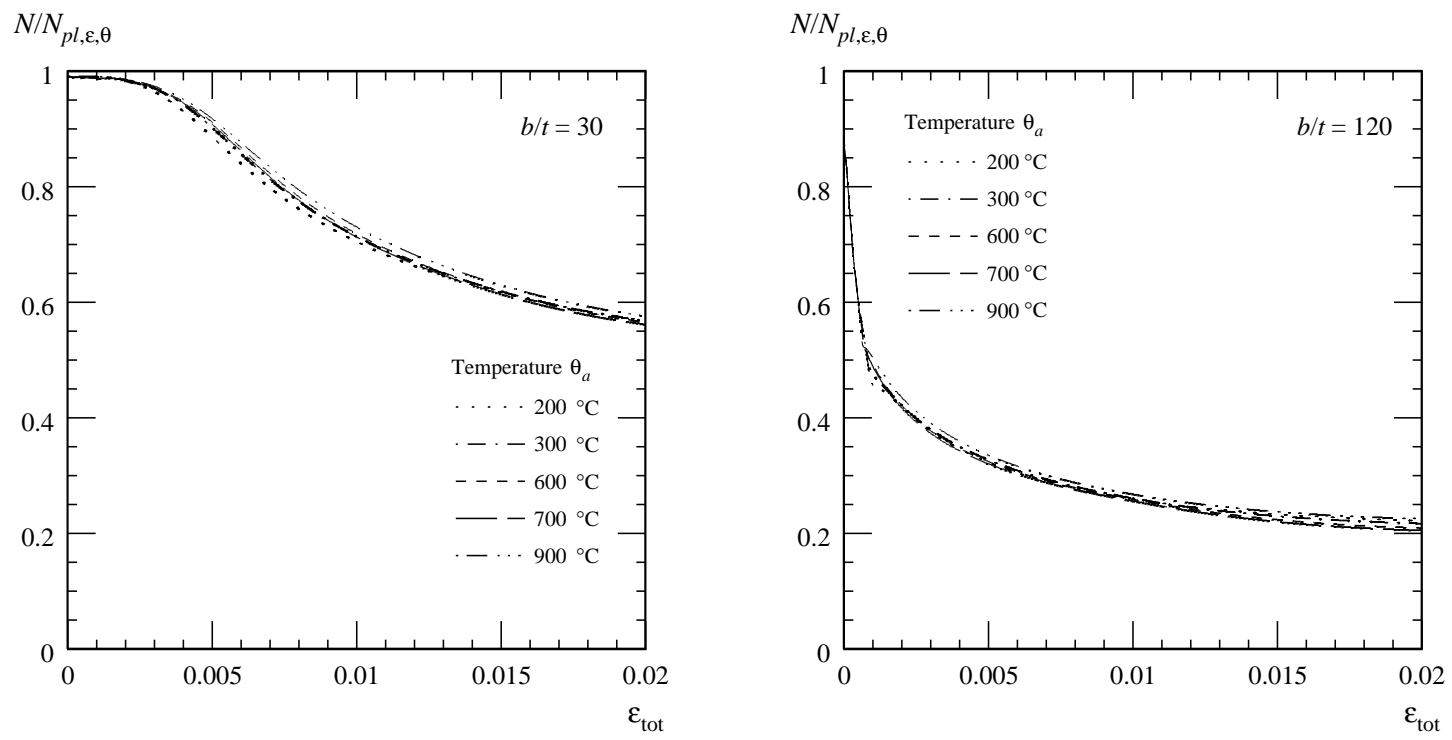

Fig. 6. Non-dimensional strain-based axial load-shortening behavior of compact (left) and slender (right) stiffened elements at elevated temperatures in fire $\left(\psi_{\varepsilon}=1.0\right)$

Figure 7 (left) shows the strain-based capacity curves for stiffened elements in uniform compression $\left(\psi_{\varepsilon}=\right.$ $1.0)$ at elevated temperatures in fire. The strain-based capacity curves are only influenced by the axial shortening $\varepsilon_{\mathrm{tot}}$, the width-to-thickness ratio $b / t$, and the equivalent geometric imperfection $e_{0, w}$. The geometric imperfections influenced the intersection point of the capacity curves with the axis of ordinates. The imperfections decreased the load-carrying capacity of the elements and avoided reaching the straindependent maximum resistance of flat elements without imperfections $\left(N / N_{p l, \varepsilon, \theta}=1\right)$ even for small strains. However, the imperfections did not influence the capacity curves for large strains and corresponding large local buckling deflections. Figure 7 (left) shows that even compact elements develop local buckling for large strains. A parametric study showed that only very stocky elements $(b / t<16)$ did not develop local buckling until reaching $2 \%$ strain in pure compression. Therefore, the simplified classification for fire design and the use of the effective yield strength reached at 2\% strain according to EN 1993-1-2 may lead
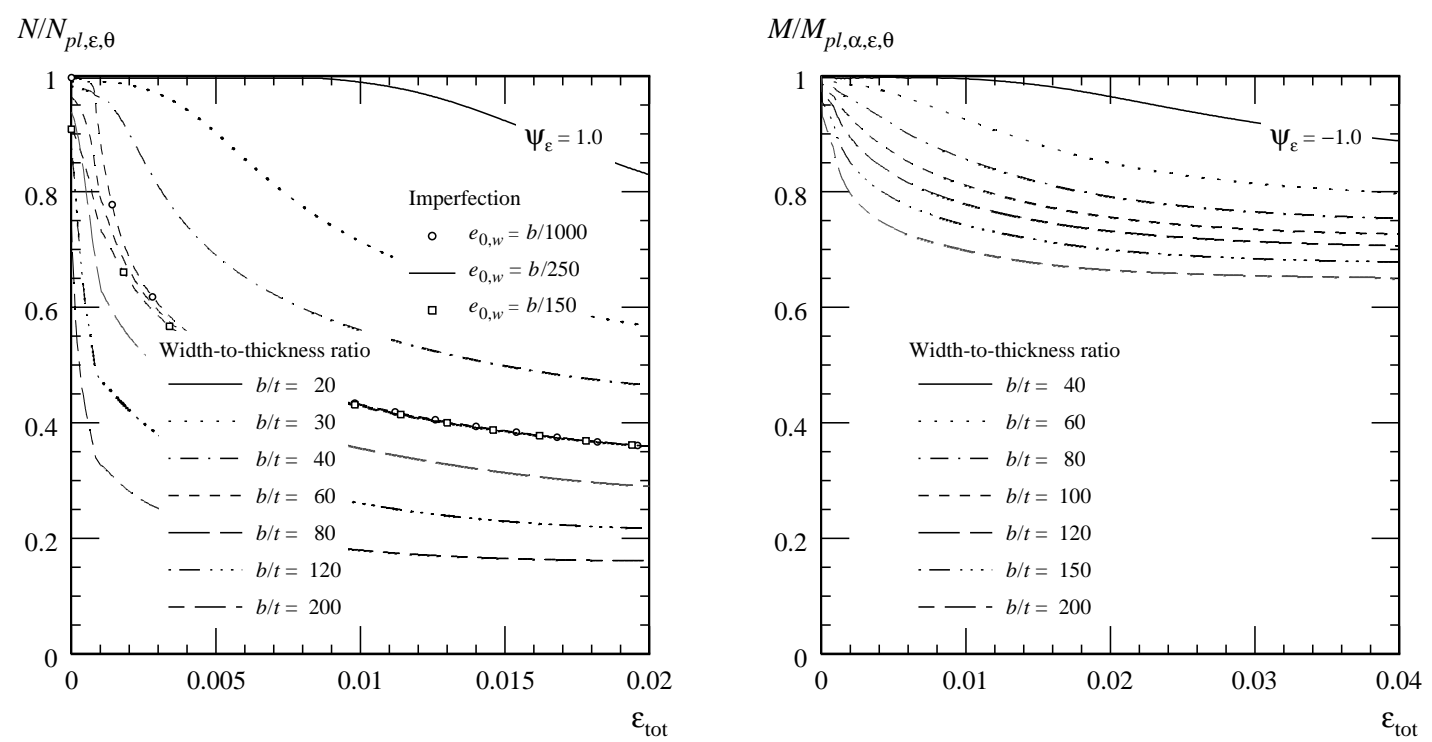

Fig. 7. Strain-based capacity curves for stiffened elements subjected to uniform compression $\left(\psi_{\varepsilon}=1.0\right)$ (left) and pure bending $\left(\psi_{\varepsilon}=-1.0\right)$ (right). 
to unconservative design results for compact elements in fire. Strain-based capacity curves could additionally be developed in the same way for stiffened elements in pure bending and combined compression and bending. Figure 7 (right) shows the strain-based capacity curves for stiffened elements subjected to pure bending $\left(\psi_{\varepsilon}=-1.0\right)$ in fire, as an example. These capacity curves for elements subjected to bending consider the temperature- and strain-dependent nonlinear stress distribution as a result of the different shapes of the nonlinear branches of the stress-strain relationship at different elevated temperatures.

Strain-based capacity curves for stiffened and unstiffened elements in fire according to Figs. 4 and 7 can be used for calculating the entire load-shortening behavior of cross-sections including their ultimate capacity. The load-shortening curves are obtained by multiplying the values of the strain-based capacity curves with the strain-dependent resistance $N_{p l, \varepsilon, \theta}$ or $M_{p l, \alpha, \varepsilon, \theta}$ (considering the strain-dependent stress distribution). Figure 8 exemplarily compares the resistance of square hollow sections RHS 150x150x5 (steel grade S235) according to the strain-based calculation model with numerical results using the finite element approach (mean value 0.98 , standard deviation 0.01 ). The numerical results were calculated on stub columns (length $=500 \mathrm{~mm}$ ) using the finite element program Abaqus [13] with 9-node shell elements (designated as S9R5 of the Abaqus element library). The numerical calculations were performed displacement controlled and the stub columns were subjected to pure compression. Further details of the numerical calculations are given in [7]. Figure 8 additionally compares the cross-sectional capacity according to EN 1993-1-2 with the numerically determined resistance (mean value 1.27 , standard deviation 0.13 ). The calculation method adopted by EN 1993-1-2 led to unconservative results, in particular for low elevated temperatures up to $400^{\circ} \mathrm{C}$. The use of the effective yield strength reached at $2 \%$ strain was the main reason for these unconservative results. Therefore, Fig. 8 additionally compares the resistance calculated with the gross cross-sectional area and the temperature-dependent 0.2\%-proof stress $f_{p, 0.2, \theta}$ (EN 1993-1-2 $2004-f_{p 0.2, \theta}$ ), usually only be used for slender cross-sections (class 4). A parametric study on stub columns (RHSsections, I-sections) and the strain-based capacity curves developed showed that the commonly used calculation methods for the fire design considering local buckling effects shall be improved. In particular, the maximum width-to-thickness ratios for classification and the use of the effective yield strength reached at $2 \%$ strain for calculating the resistance of steel sections mainly subjected to compression should be reviewed.
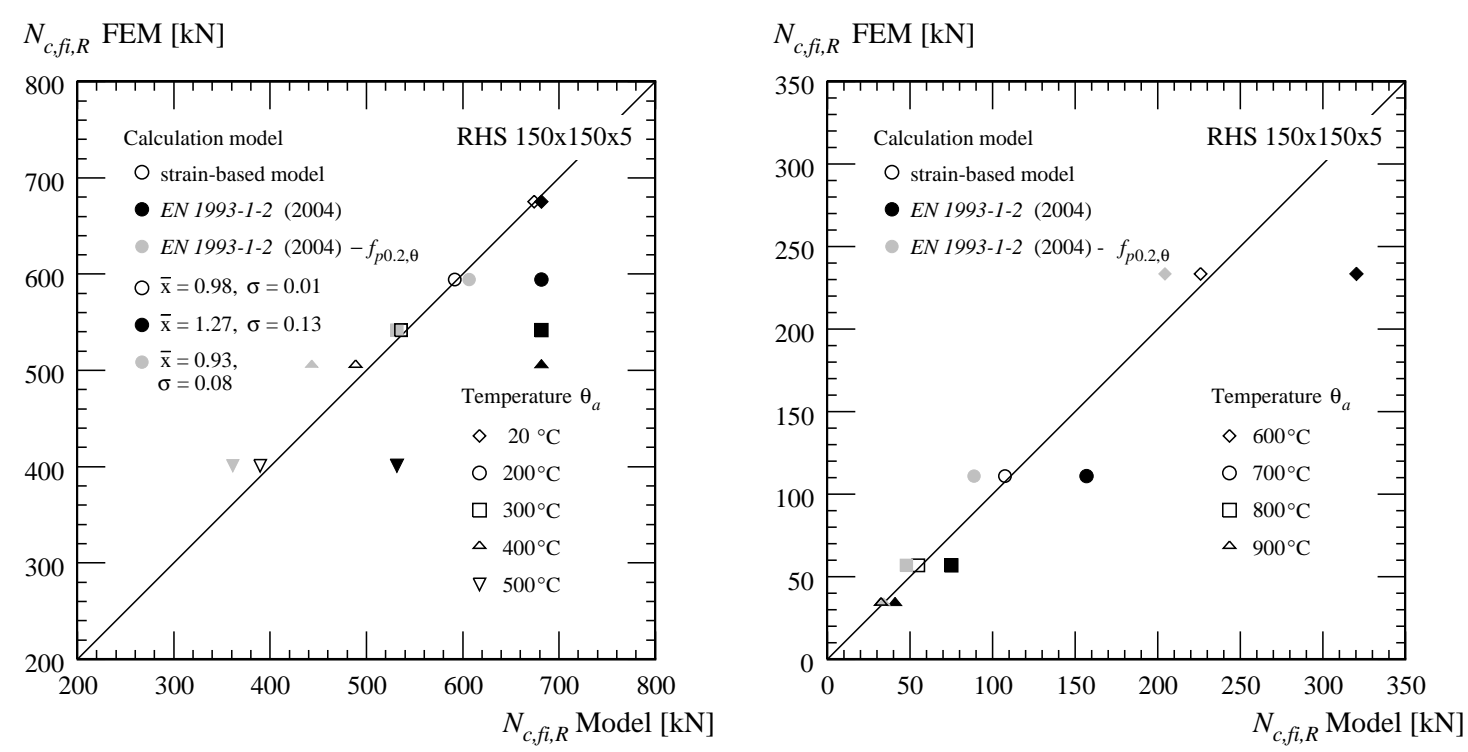

Fig. 8. Cross-section capacity of square hollow section RHS 150x150x5 (steel grade S235) subjected to axial compression at elevated temperatures - comparison between numerical results and results according to both the strain-based calculation model and EN 1993-1-2. 


\section{INFLUENCE OF HEATING ON THE LOCAL BUCKLING BEHAVIOR}

In fire, steel members heat up at a rate depending on the fire conditions. The temperature distribution of the steel cross-sections and their elements can either be uniform or non-uniform. The distribution depends on the cross-section, the fire protection and the heating conditions. The strain-based calculation model summarized in the previous section calculates the load-shortening behavior of elements in compression or bending. This model considers elevated temperatures in fire by using temperature-dependent stress-strain relationships suitable to represent conditions in standard fire tests. Calculation methods that consider the heating of the section in detail are more realistic for steel members in fire. These sophisticated models consider mechanical actions prior to ignition, thermal actions, restraining reactions due to neighboring members, and thermal creep effects, for example.

The strain-based calculation model can be extended for considering heating effects on the local buckling behavior of stiffened and unstiffened elements. The extended model uses the strain-based capacity curves (Figs. 4 and 7), considers mechanical loading prior to heating as well as thermal restraining reactions due to neighboring members and can be used for both uniform and non-uniform heating. The model assumes that thermal creep effects are sufficiently considered using temperature-dependent stress-strain relationships (e.g. EN 1993-1-2). The model further assumes that the thermal elongation of the elements during heating is not restrained in direction perpendicular to the direction of the mechanical loading, leading to thermal stresses only towards the direction of thrust. In addition, the model considers uniform temperature distributions across the thickness of the elements - approximately given for common steel sections subjected to fire - and in the longitudinal direction.

\section{Uniform heating}

This section deals with the influence of a uniform heating on the local buckling behavior of steel sections and extends the strain-based calculation model for considering uniform heating effects. The axial loadtemperature behavior, including the critical temperature, of stiffened and unstiffened elements free to expand during uniform heating can easily be calculated using the model described in the previous section. The strain-based capacity curves (Figs. 4 and 7) could additionally be used for calculating the axial loadtemperature behavior of elements with thermal restraints in fire. The thermal elongation of the elements can be partially or fully restrained by neighboring members. The degree of restraining action could be considered by using a translational spring along the width of the element possessing the spring stiffness $c_{t}$. The determination of the spring stiffness from the boundary conditions can be rather difficult; few details are given in [14]. The total strain $\varepsilon_{\text {tot }}$ of elements, whose thermal elongation towards the direction of the mechanical loading was fully restrained, resulted from the sum of the mechanical $\varepsilon_{\text {mec }}$ and the thermal strain $\varepsilon_{\text {th }}$. For stiffened and unstiffened elements with partial axial restraints, the total strain could be regarded as the sum of the mechanical and thermal strain less the strain $\varepsilon_{c}$ for considering the thermal elongation of the elements. The axial thermal elongation depended on the neighboring members and thus on the spring stiffness $c_{t}$. The ratio $N / N_{p l, \varepsilon, \theta}$ for considering local buckling effects was determined as a function of the total strain $\varepsilon_{\text {tot }}$ using the strain-based capacity curves presented in Figs. 4 and 7 . The strainand temperature-dependent strain $f_{\varepsilon, \theta}$ was also calculated as a function of the total strain $\varepsilon_{\text {tot }}$ as well as the temperature $\theta_{a}$.

Figure 9 compares, as an example, the axial load-temperature behavior of compact $(b / t=30$, left $)$ and slender $(b / t=120$, right) stiffened elements according to the strain-based calculation model to numerical results calculated using the finite element program Abaqus [13]. The axial force $N$ is given relative to the plastic resistance at ambient temperature $N_{p l, y, 20^{\circ} \mathrm{C}}$ calculated with the yield strength at ambient temperature and the gross cross-sectional area. The elements were loaded with an axial force (strain ratio $\psi_{\varepsilon}=1.0$ ) of $70 \%$ of the ultimate resistance at ambient temperature according to finite element calculations prior to uniform heating. The stress-strain relationships at elevated temperatures were taken from EN 1993-1.2 for steel grade S235. The calculations used different values of the spring stiffness ratio $k$ to model semi-rigid neighboring members providing different partial restraints. The value $k$ represents the ratio between the stiffness of the neighboring members - represented by the spring stiffness $c_{t}$ - and the stiffness of the element $\left(k=c_{t} /\left[E_{a, 20^{\circ} \mathrm{C}}(t / b)\right]\right)$. A value of $k=0$ corresponds to a free thermal elongation; a value of $k=\infty$ corresponds to fully restraint. The thermal elongation of the elements was calculated with Abaqus [13] for simplicity. 

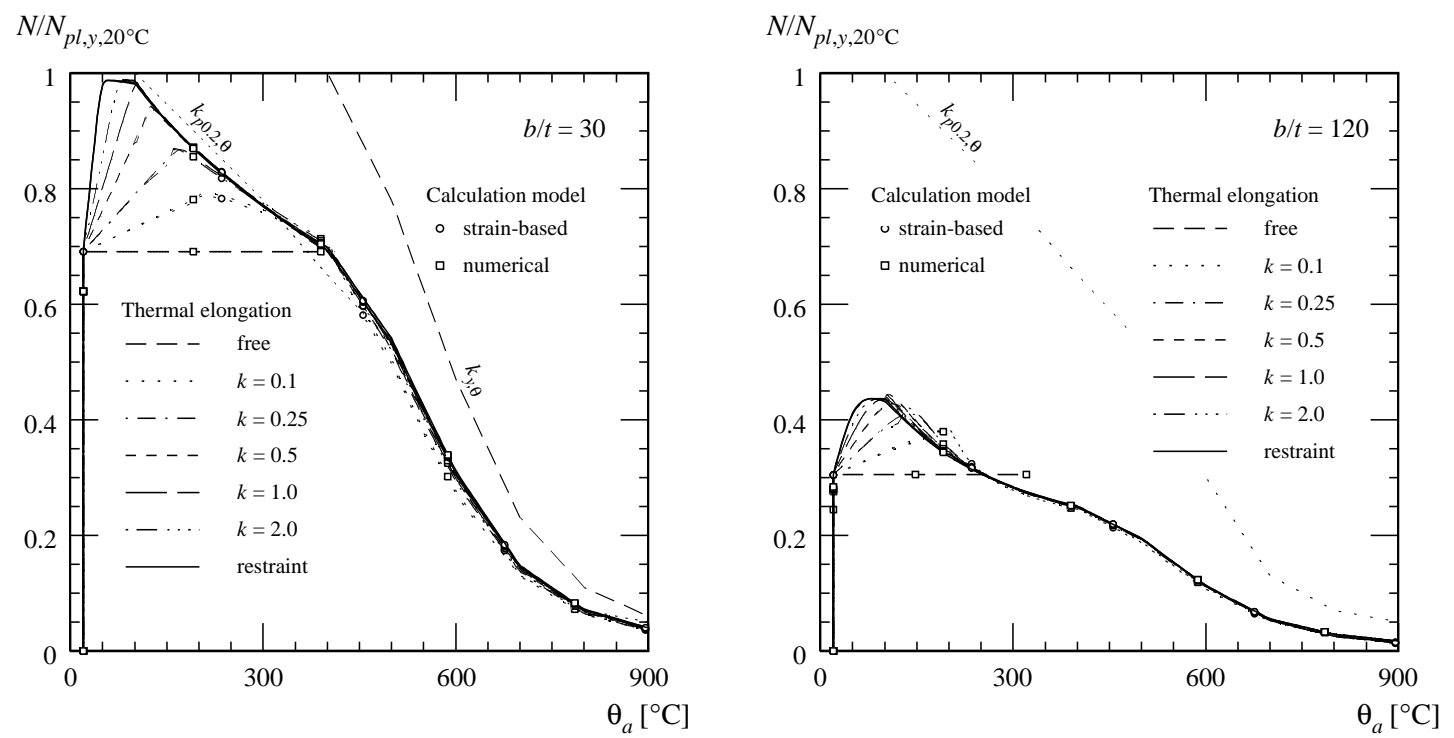

Fig. 9. Non-dimensional axial load-temperature behavior of compact $(b / t=30$, left $)$ and slender $(b / t=120$, right) stiffened elements with uniform heating for different boundary conditions for thermal elongation.

The axial load-temperature curves according to the strain-based calculation model are almost congruent to the numerical results. The stiffness ratio $k$ decisively influenced the axial load-temperature behavior. The maximum axial load increased for larger values of $k$ due to thermal restraining reactions. The value of $k$ additionally influenced the temperature corresponding to the maximum load: the temperature decreased for increasing values of $k$. The decreasing branch of the axial load-temperature curve can be regarded as the temperature-dependent maximum resistance of the stiffened elements in compression. Figure 9 (left) additionally compares the non-dimensional axial load-temperature curves to the non-dimensional stresses $k_{y, \theta}=f_{y, \theta} / f_{y, 20^{\circ} \mathrm{C}}$ (ratio of the temperature-dependent yield strength at $2 \%$ strain to the yield strength at ambient temperature) and $k_{p 0.2, \theta}=f_{p 0.2, \theta} / f_{y, 20^{\circ} \mathrm{C}}$ (ratio of the temperature-dependent $0.2 \%$ proof stress according to EN 1993-1.2 to the yield strength at ambient temperature). Figure 9 (left) shows again that the compact element $(b / t=30)$ did not reach yield strength at $2 \%$ strain due to local buckling. The temperaturedependent $0.2 \%$-proof stress could be used instead for the design of stiffened elements with a width-tothickness ratio of 30 .

The critical temperature of partially or fully restrained elements is defined as the temperature where the axial load drops below the (mechanical) axial load prior to heating. The critical temperature of compact stiffened elements was almost independent of the thermal elongation (Fig. 9 left). The parametric study showed, however, that the thermal restraints influenced the critical temperature of slender elements (Fig. 9 right). The critical temperature decreased for increasing thermal restraints (larger values of $k$ ). The loadcarrying capacities of thermally restraint stiffened elements were less than their capacities without restraints. Due to the thermal restraints the local buckling deflections were increased during heating. Larger buckling deflections decreased the load-carrying capacity and reduced the critical temperature. The behavior was similar to slender (overall slenderness) steel columns without local buckling [15]. It has to be analyzed if the low critical temperatures of slender stiffened elements can be confirmed for thin-walled cross-sections and practical applications.

\section{Non-uniform heating}

This section deals with the influence of non-uniform heating on the local buckling behavior of steel sections and extends the strain-based calculation model for considering non-uniform heating effects. Nonuniform temperature distributions of stiffened elements can be the result of fire exposures of steel crosssections on all sides or on one/three sides. Fire exposures on all sides often result in almost symmetrical temperature distributions and fire exposures on one/three sides often lead to an almost constant temperature gradient over the width of the elements (e.g. the web of a C-profile with fire exposure on one side). A nonuniform heating causes thermal stresses even for elements with free thermal elongation towards the 
direction of mechanical loading. A non-symmetrical temperature distribution results in bending moments even for elements subjected to pure mechanical compression $\left(\psi_{\varepsilon}=1.0\right)$.

The strain-based calculation model was extended to consider symmetrical non-uniform temperature distributions and non-uniform distributions with a constant temperature gradient during heating in fire. The simplified model (Fig. 10) assumed a constant mechanical strain ratio of $\psi_{\varepsilon}=1.0$ during heating. The model divided the stiffened elements into $n$ layers that are free to expand (Fig. 10a). Every layer $i$ possessed the temperature $\theta_{a, i}(\mathrm{~b})$. These temperatures resulted in free thermal strains $\varepsilon_{\mathrm{th}, i}(\mathrm{c})$. The strain ratio of $\psi_{\varepsilon}=1.0$ led to stress-producing thermal strains $\varepsilon_{\mathrm{th}, \sigma, i}(\mathrm{~d})$. The total strain $\varepsilon_{\mathrm{tot}, \sigma, i}(\mathrm{f})$ of every layer was the sum of the stress-producing thermal strain, the mechanical strain and the strain for considering the thermal restraints of the elements. The strain-dependent stress $f_{\varepsilon, \theta, i}(\mathrm{~h})$ of every layer was calculated as a function of the total strain $\varepsilon_{\mathrm{tot}, \theta, i}$ using the temperature-dependent stress-strain relationship (g). The ratio $N / N_{p l, \varepsilon, \theta}$ for considering local buckling effects was determined as a function of the maximum total strain $\varepsilon_{\text {tot, },, i, \max }$ and the width-to-thickness ratio $b / t$ using the strain-based capacity curves presented in Fig. 10 (i). The axial load of the element was calculated as the product of the ratio $N / N_{p l, \varepsilon, \theta}$ for considering local buckling effects and the strain- and temperature-dependent maximum resistance.

(a)

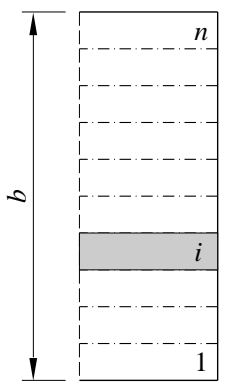

(g)

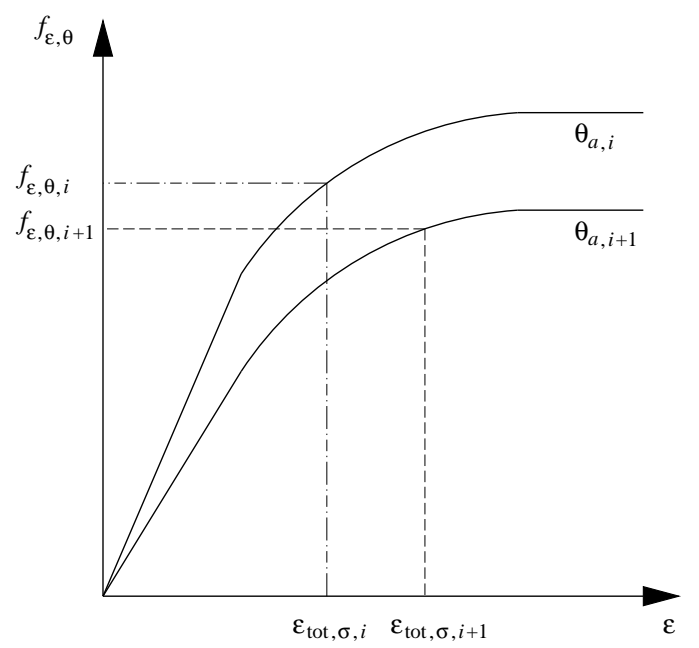

(d)

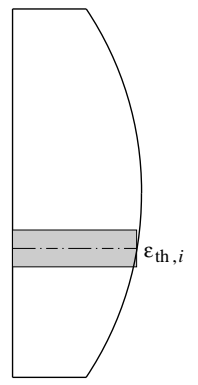

$\varepsilon_{\text {th }}$

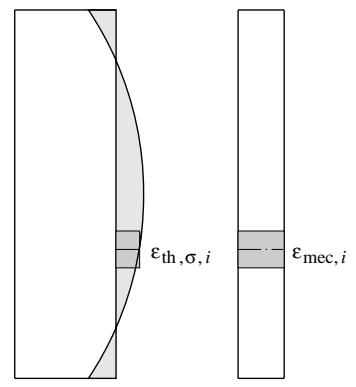

$\varepsilon_{\text {th }, \sigma}$ (f)

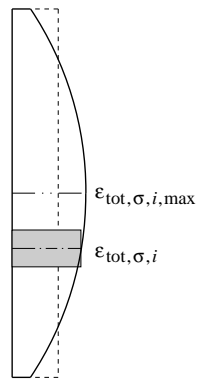

$\varepsilon_{\text {tot, } \sigma}$ (h)

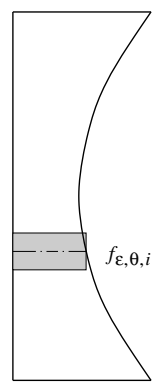

$f_{\varepsilon, \theta}$

(i)

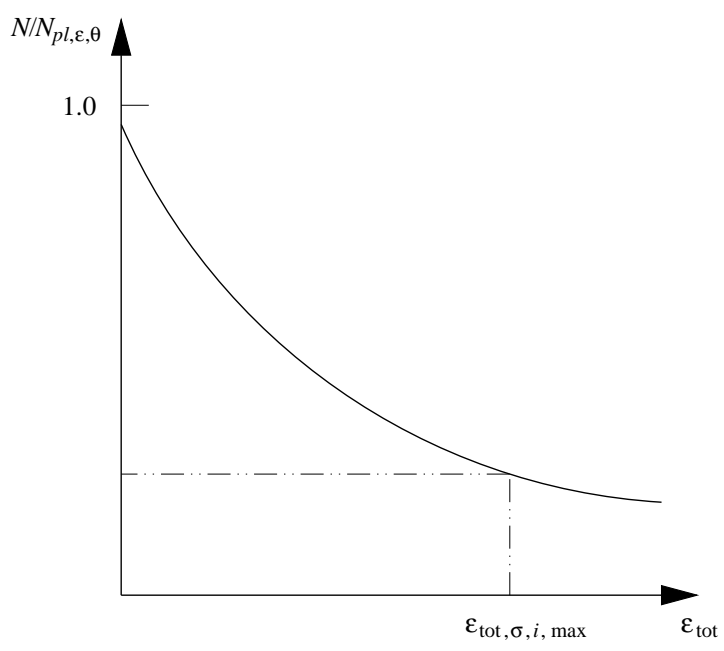

Fig. 10. Layer model for stiffened elements with non-uniform temperature distribution. (a) Layers of the element; (b) temperature distribution; (c) free thermal strain; (d) stress-producing thermal strain; (e) mechanical strain; (f) stress-producing total strain; (g) temperature-dependent stress-strain relationship; (h) stress distribution and (i) strain-based capacity curve. 
The simplified calculation model was verified with results of a numerical parametric study using the finite element program Abaqus [13]. The stiffened elements were loaded with an axial force $\left(\psi_{\varepsilon}=1.0\right)$ prior to heating. The mechanical load corresponded again to $70 \%$ of the ultimate resistance at ambient temperature. Figures 11 and 12 exemplarily compares the axial load-maximum temperature behavior for compact (left) and slender (right) stiffened elements according to the strain-based calculation model to the results of the finite element calculations. The temperature increased uniformly from a uniform temperature of $20^{\circ} \mathrm{C}$ to a sinusoidal (Fig. 11) and triangular shaped (Fig. 12) temperature distribution. The maximum temperature (after heating) of the sinusoidal shaped distribution was $650^{\circ} \mathrm{C}$ in the middle of the element. The minimum temperatures at the edges were $500^{\circ} \mathrm{C}$ (after heating). The temperature difference between the middle and the edges of the element varied during heating from $0 \mathrm{~K}$ at the beginning to a maximum difference of $150 \mathrm{~K}$ after the heating. The maximum temperature of the triangular shaped distribution continuously varied from $700^{\circ} \mathrm{C}$ at the edges to $750^{\circ} \mathrm{C}$ in the middle of the element after the heating (maximum temperature difference $50 \mathrm{~K})$.

The simplified strain-based calculation model slightly overestimated the influence of the local buckling effect on the axial load-temperature behavior for a large difference in temperature between the middle of the element and its edges (Figs. 11 and 12). The difference in temperature increased during heating and was larger for the sinusoidal shaped temperature distribution (Fig. 11) than for the triangular shaped distribution (Fig. 12). The simplified model determined the local buckling effect as a function of the maximum stressproducing total strain. The difference in strain (between the middle of the element and its edges) was neglected for the influence of local buckling on the temperature-dependent load-carrying capacity. The use of the maximum strain therefore resulted in lower values of the axial load.
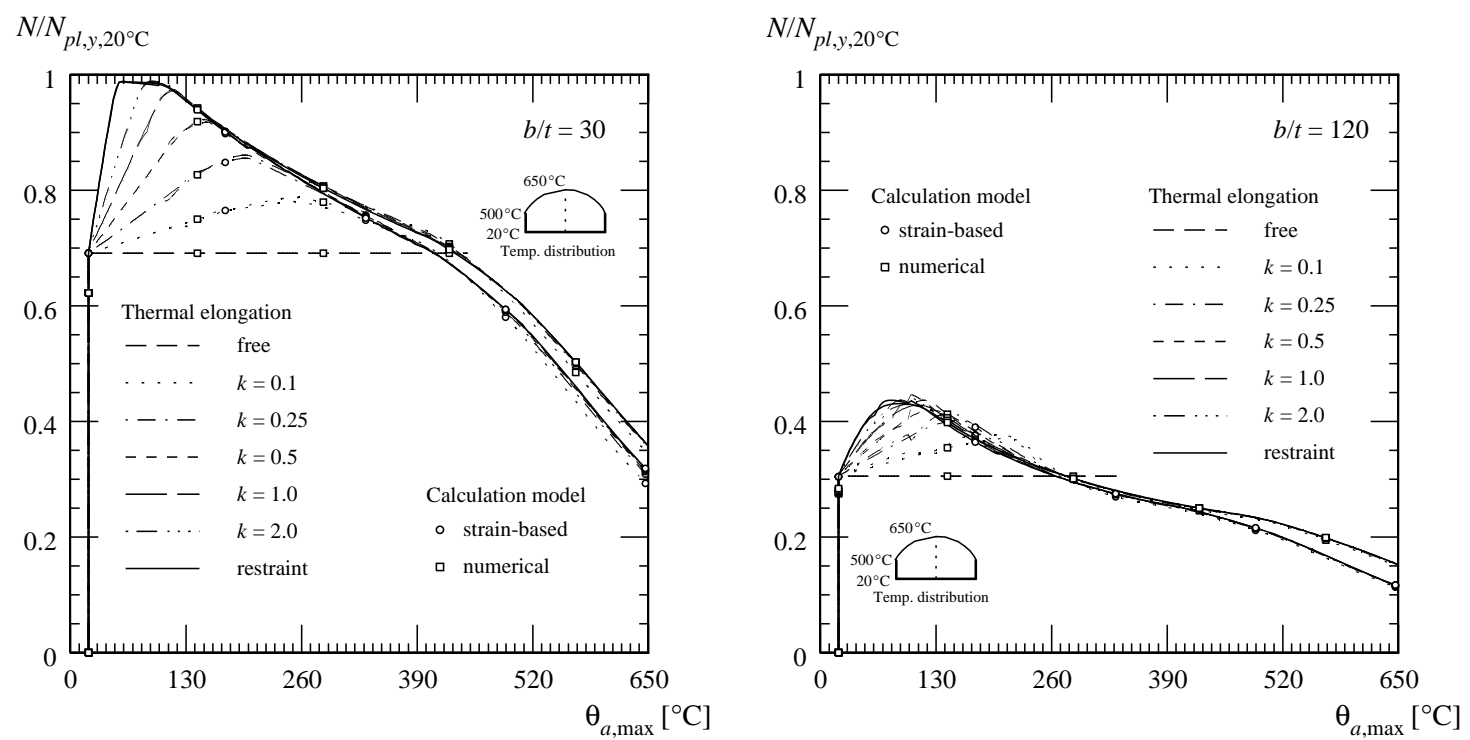

Fig. 11. Non-dimensional axial load-maximum temperature behavior of compact (left) and slender (right) stiffened elements with sinusoidal shaped temperature distribution according to the strain-based model and finite element calculations. 

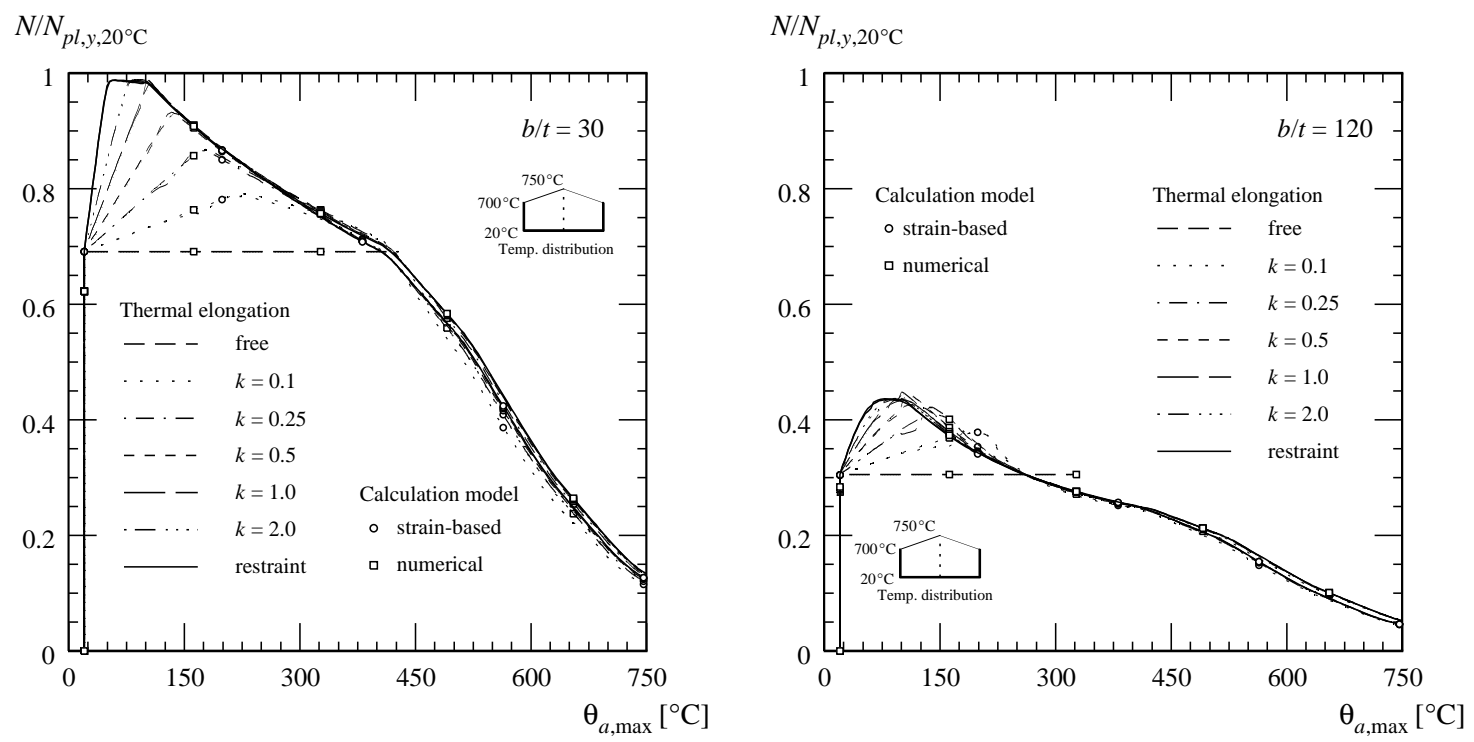

Fig. 12. Non-dimensional axial load-maximum temperature behavior of compact (left) and slender (right) stiffened elements with triangular shaped temperature distribution according to the strain-based model and finite element calculations.

The extended strain-based calculation model (Fig. 10) can also be used for calculating the load-maximum temperature behavior of stiffened elements with a constant temperature gradient over their widths. Figure 13 shows the non-dimensional axial load-maximum temperature behavior (left) and the corresponding bending moment-maximum temperature behavior (right) of compact stiffened elements $(b / t=30)$ for a fire exposure from one/three sides as an example. The behaviors are given according to the strain-based model and numerical calculations using the finite element approach. The axial load and the bending moment are given relative to their corresponding resistances at ambient temperature considering plastic stress distribution for the bending resistance. The temperature increased steadily from a uniform temperature of $20^{\circ} \mathrm{C}$ to a trapezoidal shaped distribution with maximum temperature of $700^{\circ} \mathrm{C}$ and $300^{\circ} \mathrm{C}$ respectively at the edges of the element (after heating). A positive bending moment characterized a shift of the neutral axis towards the colder edge of the element. The trapezoidal temperature distribution led to negative bending moments and a shift of the neutral axis towards the warmer edge during heating for temperatures below $100^{\circ} \mathrm{C}$. The strength and stiffness of steel below $100^{\circ} \mathrm{C}$ remained unchanged [1]. Therefore, the entire element possessed equal material properties during the first heatingphase. The larger thermal strains within the warmer region of the element led to larger strain-dependent stresses $f_{\varepsilon, \theta, i}$ and a shift of the neutral axis towards this edge. During the second heating phase, for temperatures above $100^{\circ} \mathrm{C}$ the shift of the neutral axis returned and the axis shifted towards the colder edge of the element. In this second phase, the strength and stiffness within the warmer region were more reduced than within the colder region. The neutral axis shifted towards the colder edge of the element, although the difference between the thermal strains still increased due to the larger differences in temperature. The strain-based calculation model considered all these effects and was able to calculate the axial load- and corresponding bending moment-temperature behavior, although the simplified method neglected local buckling effects on the bending momenttemperature behavior for simplicity. 

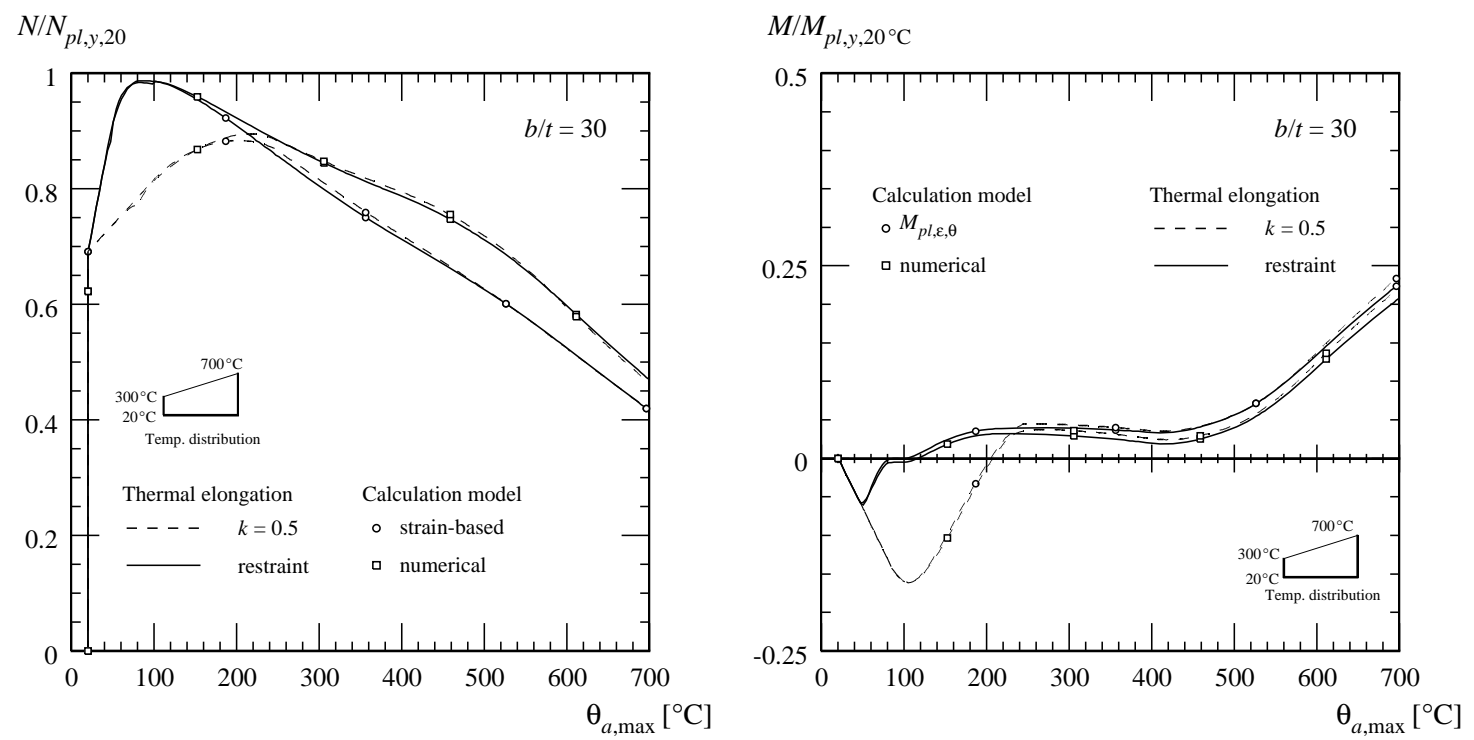

Fig. 13. Non-dimensional axial load-maximum temperature behavior (left) and corresponding bending moment-maximum temperature behavior (right) of compact stiffened elements $(b / t=30)$ with trapezoidal shaped temperature distribution.

\section{CONCLUSIONS}

Local buckling, the non-linear stress-strain relationship of steel at elevated temperatures, thermal strains and stresses, and non-uniform temperature distributions have a strong influence on the load-carrying behavior of steel sections subjected to fire. Under fire conditions, local buckling needs to be considered for more cross-sections than in ambient temperature design. The paper has shown that even compact sections suitable for plastic design at ambient temperature develop local buckling in fire. Commonly used calculation methods using the effective width method have difficulty describing local buckling in fire, especially for compact sections. It is necessary to review the current classification and the calculation methods using the effective yield strength reached at $2 \%$ strain for fire design. Strain-based calculation methods are more suitable for fire design. The paper has analyzed the local buckling behavior of steel sections in fire using a novel strain-based calculation model proposed for calculating the resistance of stiffened and unstiffened elements. The model uses strain-based capacity curves, and facilitates the calculation of the entire load-shortening behavior, including the decreasing branch. The strain-based model avoids classification and can be used for all sections. It considers the nonlinear stress-strain relationship of steel at elevated temperatures, non-uniform temperature distributions, and thermal strains and stresses. The novel calculation model accords well with results obtained from a parametric study which applies the finite element approach.

\section{REFERENCES}

[1] EN 1993-1-2: 2005. Eurocode 3: Design of steel structures - Part 1-2: General rules - Structural fire design.

[2] Ala-Outinen, T. and Myllymäki, J., The local buckling of RHS members at elevated temperatures, VTT Research Notes 1672, Technical Research Centre of Finland, Espoo, 1995.

[3] Ranby, A., Structural Fire Design of Thin Walled Steel Sections, Licentiate Thesis, Lulea University of Technology, Lulea, 1999.

[4] Feng, M. and Wang, Y.C., 2005. An analysis of the structural behaviour of axially loaded fullscale cold-formed thin-walled steel structural panels tested under fire conditions. Thin-Walled Structures 43(2): 291-332, doi: 10.1016/j.tws.2004.07.008. 
[5] Heidarpour, A. and Bradford, M.A., 2007. Local buckling and slenderness limits for flange outstands at elevated temperatures. Journal of Constructional Steel Research 63(5): 591-598, doi: 10.1016/j.jcsr.2006.07.007.

[6] Brune, B., 2000. Die Methode der wirksamen Breiten und ihre Anwendung beim Nachweisverfahren Plastisch-Plastisch [The method of effective widths and its use for the calculation plastic-plastic]. Stahlbau 69(3): 191-201.

[7] Knobloch, M., Zum Tragverhalten beulgefährdeter Stahlquerschnitte bei Brandeinwirkung [On the load-carrying behavior of steel sections subjected to local buckling and fire], ETH Zurich, IBK report No. 303 and PhD Thesis No. 16910, Zurich, 2007.

[8] Kármán, Z. von, Sechler, E.E., and Donnell, L.H., 1932. The strength of thin plates in compression. Transactions ASME 54: 33-57.

[9] Knobloch, M. and Fontana, M., 2006. Strain-based approach to local buckling of steel sections subjected to fire. Journal of Constructional Steel Research 62(1-2): 44-67, doi:10.1016/j.jcsr.2005.04.007.

[10] Knobloch, M. and Fontana, M., 2005. Load-carrying Behavior of Unstiffened Elements at Elevated Temperatures in Fire. Fire Safety Science 8: 223-234, doi:10.3801/IAFSS.FSS.8-223.

[11] Murray, N.W. and Khoo, P.S., 1981. Some basic plastic mechanisms in the local buckling of thinwalled steel structures. International Journal of Mechanical Science 23(12): 703-713.

[12] Rusch, A., Tragfähigkeit von beulgefährdeten, normalspannungsbeanspruchten I-Profilen, Shaker, Aachen, 2000.

[13] Abaqus, Rel. 6.5-4, Hibitt, Karlson and Sorensen Inc., 2005.

[14] Wong, M.B., 2005. Modeling of axial restraints for limiting temperature calculation of steel members in fire. Journal of Constructional Steel Research 61(5): 675-687, doi: 10.1016/j.jcsr.2004.10.003.

[15] Cabrita Neves, I., 1995. The Critical Temperature of Steel Columns with Restrained Thermal Elongation. Fire Safety Journal 24(3): 211-227, doi: 10.1016/0379-7112(95)00026-P. 